\title{
A história e registo dos encontros da AULP: Atas
}

\author{
Cristina Montalvão Sarmento
}

Secretária-Geral da AULP (2006-2010; 2014-2016)

Professora do Instintuto Superior de Ciências Sociais e Política da Universidade de Lisboa

\section{Pandora Guimarães}

Gabinete de Comunicação da AULP Mestranda em Comunicação, Cultura e Tecnologias da Informação, ISCTE-IUL

\section{Os primeiros encontros em território português}

O primeiro encontro da AULP tem lugar na Universidade de Lisboa, Portugal, três anos depois da sua fundação. Na necessidade de reunir em livro as comunicações apresentadas durante os Encontros, nos diversos painéis temáticos, bem como uma listagem dos participantes, o conselho de administração decidiu criar esta coleção após o II Encontro da AULP, em Évora, em 1990.

Com o tema "Ciência e Tecnologia nos Processos de Desenvolvimento", surge assim o primeiro livro de atas, com uma tiragem de 1000 exemplares, quatro anos após a fundação da associação, registando a evolução de uma organização que aumentava a sua notoriedade nos países de língua portuguesa e Macau: “das 10 instituições fundadoras de Novembro de 1986 estamos atualmente em mais de setenta"1.

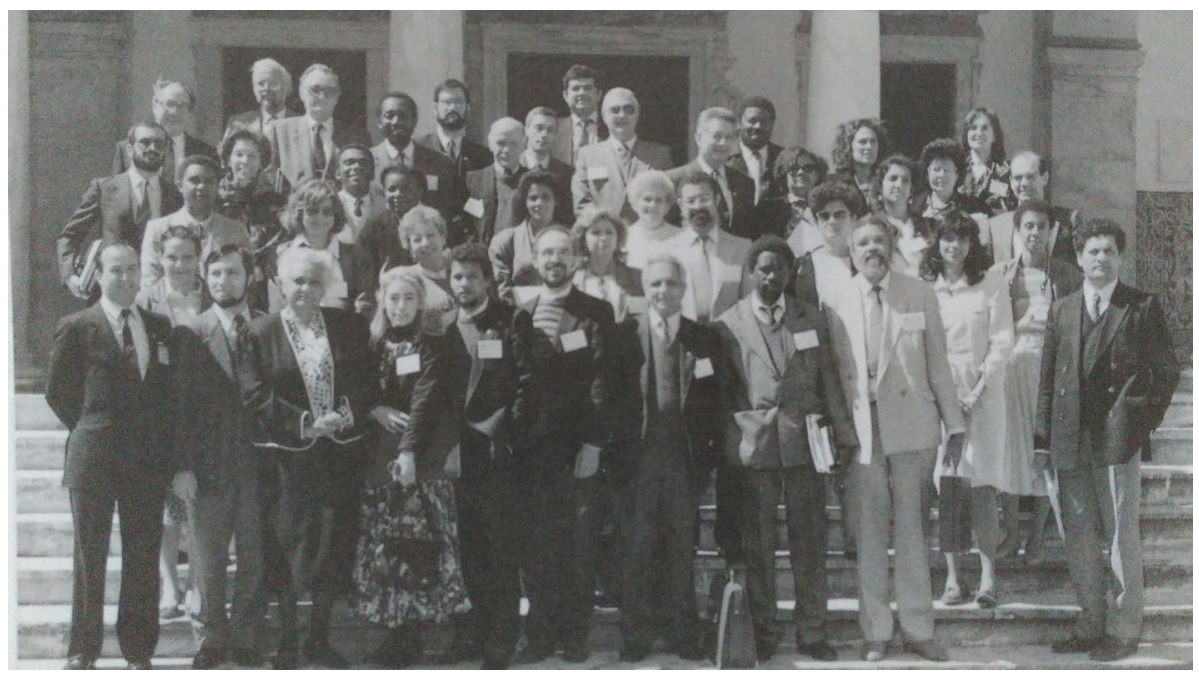

1 - Participantes do II Encontro da AULP - Reitoria da Universidade de Évora, Abril 1990. Fotografia publicada na primeira página do primeiro livro de atas. Os livros seguintes mantiveram essa tradição até ser impossível tirar fotografias de grupo devido ao elevado número de participantes que foi aumentando ao longo dos anos.

1. Discurso de António Simões Lopes, Vice-Presidente da AULP, na sessão de abertura do II Encontro da AULP. 
126 | RILP - Revista Internacional em Língua Portuguesa - nº 30 - 2016

Até à data foram publicados 23 números - estando atualmente em edição o livro referente ao XXVI Encontro da AULP em Timor-Leste, - sendo que I e o VII não tiveram livro de atas. Em 1997, o VII Encontro da AULP decorreu no Rio de Janeiro, Brasil, e as comunicações perderam-se pelo que não foi possível compilá-las. Já o ano anterior, 1996, VI Encontro, em Lisboa, Portugal, foi o único ano em que as comunicações foram reunidas e impressas num caderno e não em livro.

Dado que a sede da AULP se encontra, por obrigação estatutária, em território português, os primeiros 4 encontros decorreram em Portugal. Se inicialmente decorreram de 2 em 2 anos, rapidamente os encontros se tornaram conferências anuais a partir de 1994. Estoril (Portugal) foi palco do III e IV Encontro, 1992 e 1994 respetivamente. Em 1992, a publicação foi subordinada ao tema "Ciência e Tecnologia nos Processos de Desenvolvimento: os Recursos e as Infraestruturas" e em 1994 a edição focou a problemática da gestão dos recursos humanos no ensino superior, os recursos naturais, as infraestruturas e o desenvolvimento bem como o turismo como fator de desenvolvimento foram objeto de análise pelos diversos oradores do espaço lusófono.

Só em 2000 é que Portugal acolhe novamente o Encontro anual da AULP. Rumo a Ponta Delgada, Portugal, sob os auspícios da Universidade dos Açores, ocorreu o X Encontro para discutir "O Ensino Superior na Sociedade do Século XXI". A edição do livro de atas referente a esse encontro constitui o relatório científico do debate académico desencadeado em torno da problemática universitária e sua integração dinâmica na sociedade, o ensino superior e a sua articulação com o ensino secundário, as novas tecnologias de informação e comunicação, a diversificação do ensino superior e as políticas de cooperação académica entre as instituições de ensino superior dos países de língua portuguesa.

"Novas Políticas para o Ensino Superior" é o livro de atas que reúne as comunicações apresentadas durante o XI Encontro Anual, 2001, realizado em Viseu, Portugal, onde foram analisadas questões relacionadas com a responsabilidade social das instituições de ensino superior e sua relação com a comunidade, as políticas de ensino superior e de investigação bem como as dinâmicas de cooperação académica e institucional entre as universidades do espaço lusófono.

O regresso à capital de Portugal, Lisboa, dá-se em 2005. "Novos Desafios no Espaço do Ensino e Investigação dos Países de Língua Portuguesa" reúne as comunicações apresentadas durante o XV Encontro, em que as sessões plenárias e as comunicações apresentadas giraram em torno das temáticas do "Espaço Lusófono de Ensino Superior e Investigação", da "Saúde e Sociedade", das "Tecnologias de Informação - Desenvolvimento Científico e Impactos Sociais e Económicos", "Ciências Agrárias: Ensino, Investigação e Desenvolvimento" e "Língua Portuguesa e Multiculturalismo". 
O último encontro em Portugal foi em Bragança, 2011. O livro de atas reúne as comunicações apresentadas durante o XXI Encontro da AULP, subordinado à temática - "Novas Formas de Cooperação: Espaços de Convergência nos Países Lusófonos". "Os temas escolhidos para o Encontro são cruciais para a missão das instituições de ensino superior no aprofundamento da Lusofonia: mobilidade académica, creditação e múltipla titulação de graus académicos, modalidades de cooperação e programas de financiamento na investigação científica e transferência de conhecimento no âmbito de parques tecnológicos, incubadoras e empreendedorismo, permitirão novos espaços de convergência no seio da CPLP e um melhor conhecimento interinstitucional, com vantagens ao nível da competitividade universitária mundial", como afirmou, João Sobrinho Teixeira, Presidente do Instituto Politécnico de Bragança.

\section{O Brasil como palco das conferências}

Com o primeiro encontro no Brasil, Recife, 1995, o livro de atas reuniu os artigos e as comunicações apresentadas durante o V Encontro da AULP, sujeito ao tema "Sistema de Ensino no Processo de Desenvolvimento". Para além da reflexão sobre a importância do sistema de ensino no processo de desenvolvimento dos países de língua portuguesa, temáticas como a cultura e o desenvolvimento no espaço lusófono, a cooperação universitária e o ensino superior foram objeto de análise aprofundada pelos diversos intervenientes no processo de construção do espaço lusófono do ensino superior. Dois anos depois, a AULP volta a reunir no Brasil, desta vez no Rio de Janeiro que, à exceção do primeiro encontro foi o único que não ficou registado em livro de atas.

A AULP só regressa ao Brasil sete anos depois, em 2004, a São Paulo, no XIV Encontro. O debate centrou-se à volta da temática - "Espaço Lusófono do Conhecimento" - e as discussões privilegiaram a questão da problemática da Universidade enquanto fator de desenvolvimento e combate à pobreza e a necessidade de uma cooperação académica efetiva entre os países de língua portuguesa, por intermédio da prossecução de convénios de cooperação em áreas como o ensino da língua portuguesa, a formação de professores para o ensino médio e fundamental, as ciências da saúde e as ciências agrárias, sem prejuízo de quaisquer articulações com outros domínios do conhecimento.

Em 2008, Brasília foi escolhido para acolher o XVIII Encontro da AULP com o tema "Ciência, Tecnologia e Desenvolvimento". Numa época em que o conhecimento evolui com uma extraordinária rapidez e na qual novas linhas de I\&D são sucessivamente abertas. A qualificação das atividades, a procura de novos materiais, a melhor manipulação da dimensão, a cuidada intervenção no ambiente ou a valorização do que está na fronteira da ciência constituem hoje domínios simultaneamente aliciantes e exigentes que permitem, assim esperemos, melhorar 
128 | RILP - Revista Internacional em Língua Portuguesa - nº 30 - 2016

a vida dos povos à superfície da terra. As universidades, como entidades produtoras e disseminadoras de ciência, encontram-se no cerne do desenvolvimento científico e tecnológico. As suas relações com as empresas, associações e outras instituições multiplicam-se e os programas de trabalho conjuntos ou convergentes passaram a constituir um quadro estratégico sólido que marca na atualidade o desempenho das universidades. O Encontro pretendeu debater os problemas relacionados com o desenvolvimento da investigação científica, a densificação das redes temáticas, os critérios de financiamento da I\&D, a cooperação internacional, bem como as questões institucionais relacionadas com a transferência de conhecimento e da inovação, dando uma particular atenção a dois sectores, o da biotecnologia e o da energia, e refletindo sobre os padrões futuros de desenvolvimento destes domínios e procurando identificar as potencialidades da maior colaboração universidade-empresa, passíveis no futuro de maior aprofundamento. No seu painel final, abordou-se a problemática da Língua, Cultura e Tecnologia, refletindo sobre a necessidade de valorização da língua como instrumento de cultura e de melhor relacionamento nos âmbitos científico, tecnológico, artístico, cultural e diplomático entre os povos dos países da CPLP.

O XXIII Encontro da AULP, subordinado à temática - "Cooperação e Desenvolvimento nos Países de Língua Portuguesa - o Papel das Universidades", realizou-se em Belo Horizonte, Minas Gerais (Brasil). O discurso de abertura do Presidente da AULP e Reitor da Universidade Lúrio, Professor Doutor Jorge Ferrão, expressa bem a importância do regresso ao Brasil em 2013 para realizar a conferência. "Regressamos ao Brasil e à cidade de Belo Horizonte, berço de heróis como Tiradentes, Luís Gonzaga e outros membros da Confidência Mineira, que espalharam por esta terra, pelo Brasil e por alguns dos da CPLP a sua bravura, valentia e determinação. Belo Horizonte não é, então, somente mais uma cidade ou a capital de um Estado. Belo Horizonte é o berço de todas as lutas de libertação e afirmação de vários povos e países. Realizamos esta XXIII reunião anual da AULP, num contexto de profundas e rápidas alterações dos cenários políticos e económicos regionais e globais. Se por um lado se abriram novas e promissoras perspetivas de prosperidade, crescimento económico, democracia e paz, por outro, continuamos a enfrentar grandes desafios e ameaças. Por esta razão nos reunimos em torno do tema cooperação e desenvolvimento e o papel do ensino superior na CPLP. Nesta perspetiva, estamos conscientes do papel que os governos, sociedade civil, diferentes organizações e naturalmente as instituições de ensino superior podem e devem desempenhar para minimizar os riscos e as ameaças. As IES, em particular as universidades, tem o poder e o dever de induzir a melhoria das condições de vida dos povos, dos nossos países e continentes. Pode parecer repetitivo, porém, vivemos num mundo marcado por avanços científicos e tecnológicos. Estes são tempos de mudança que ampliam a integração, encurtam distâncias 
e aproximam povos e culturas. Ainda assim, testemunhamos a exclusão social, desigualdades de vária ordem, marginalização e tendências menos ou antidemocráticas. Agora que a crise se generaliza parece evidente que recai sobre as IES a responsabilidade de alterar e engendrar um novo cenário e ordem. Nesta era de conhecimento e progresso material deveremos repensar sobre como estender os frutos a milhões de pessoas excluídas e fazer com que elas participem com os mesmos direitos em todos os processos. Devemos forçar novas agendas de desenvolvimento, mais compatíveis com a promoção dos direitos humanos e a sustentabilidade dos recursos e ambiental. Portanto, depende das IES propiciar a ordem, prosperidade, segurança social e sobretudo uma cooperação baseada no respeito e progresso.", Professor Doutor Jorge Ferrão, Presidente da AULP e Reitor da Universidade Lúrio.

\section{A solidez de Macau}

Macau recebe o Encontro pela primeira vez em 1998, no VIII Encontro. As sessões plenárias do Encontro e as comunicações apresentadas gravitaram em torno de temáticas como o ensino do português como língua estrangeira, o ensino superior e os desafios da globalização, a tríade investigação, desenvolvimento e cooperação bem como a relação dinâmica entre ensino, investigação e as novas tecnologias de informação e comunicação.

Cinco anos depois, 2003, Macau volta a receber o XIII Encontro Anual. Nesta reunião o debate científico centrou-se em torno da constituição do "Espaço Lusófono do Ensino Superior e Investigação" nos países de língua portuguesa, contendo reflexões académicas sobre a situação atual e os desafios inerentes ao futuro do ensino superior na Região Administrativa Especial de Macau, a mobilidade de docentes e de investigadores no espaço lusófono, assim como o ensino da língua portuguesa como língua estrangeira na região da ásia-pacífico.

Em 2006, tendo como anfitriã a Universidade de Macau, para além da reflexão sobre o espaço lusófono de ensino superior e de investigação, temáticas como a situação da língua portuguesa no mundo, o multiculturalismo e a cooperação económica, bem como a problemática do ensino superior, a investigação, a mobilidade de docentes e alunos foram objeto de discussão pública entre as universidades que comungam a língua portuguesa. Paralelamente ao XVI Encontro da AULP realizou-se também o Fórum para a Cooperação Económica entre a China, Macau e os Países de Língua Portuguesa com o intuito de estreitar os laços de cooperação entre a China e o espaço lusófono.

"A China, Macau e os Países de Língua Portuguesa", foi o tema do XIX Encontro da AULP, 2010, que volta a reunir-se no oriente, em Macau. Com especial relevância sobre as ligações multilaterais entre a China, Macau e os Países de Língua Portuguesa, foram analisadas as relações económicas e comerciais nas 
diversas vertentes de cooperação. Alguns dos desafios do mundo lusófono são perspetivados através dos problemas da saúde pública, agricultura, alimentação, ou ainda, do ambiente e dos recursos hídricos, ponto da nossa agenda comum. Nas sessões dedicadas à Língua Portuguesa abordaram-se as dificuldades relacionadas com a sua internacionalização, tradução, interpretação e os reflexos normativos nos sistemas jurídicos de matriz comum aos Países de Língua Portuguesa. No final, numa sessão dedicada às redes de cooperação no Ensino Superior, convidaram-se os membros da AULP a apresentarem os seus programas porquanto estiveram presentes, como convidados da Universidade de Macau, algumas das nossas congéneres da República Popular da China e Taiwan. Paralelamente ao Encontro, realizaram-se atividades de índole cultural nomeadamente a mostra de edições da AULP e o lançamento da edição comemorativa DITEMA - Dicionário Temático de Macau, Volume I, uma iniciativa da Universidade de Macau. A visita turística à RAEM e ainda facultativamente a Exposição Universal de Shangai - China 2010 - "Melhores Cidades, Maior Qualidade de Vida", constaram do programa.

Finalmente, mais recentemente, 2014, a AULP regressa a Macau para realizar a XXIV reunião anual, com o tema "A importância da divulgação das línguas portuguesa e chinesa para a colaboração académica no ensino superior". "Macau ocupa um papel de inegável relevo e importância histórica no milenar diálogo civilizacional entre o oriente e o ocidente e hoje, também, com o continente africano. Portanto, esse papel não se resume ao passado, mas e fundamentalmente, ao presente e ao futuro. O futuro deste pequeno pedaço de terra continuará sendo ponto de referência incontornável e uma verdadeira plataforma que promove as nossas relações culturais, religiosas, científicas, comercias e diplomáticas, sobretudo entre o espaço de expressão portuguesa e a Grande China. Realizamos esta XXIV reunião anual da AULP ainda num contexto de profundas e rápidas alterações dos cenários políticos e económicos regionais e globais. A China e Macau têm sido parte integrante desta cooperação e mudanças. Se por um lado se abriram novas e promissoras perspetivas de prosperidade, crescimento económico, democracia e paz, por outro, continuamos enfrentando grandes desafios e ameaças. Estes os tempos de mudança que ampliam a integração entre os povos, encurtam distâncias e aproximam as línguas e culturas. Nos reunimos, então, em torno do tema a importância da divulgação das línguas portuguesa e chinesa para a colaboração académica no ensino superior. Macau tem jogado um papel importante neste processo, sobretudo por facilitar os contactos e os investimentos da China, principalmente, nos países africanos de expressão oficial portuguesa. O sonho de construção de sociedades mais justas, equitativas e de progresso social se transforma, gradualmente, em realidade. Temos vindo a minimizar as diferenças entre os nossos países atingindo níveis minimamente aceitáveis no 
contexto do desenvolvimento educacional, cultural, artístico, económico e social. Porém, continuamos distantes do ótimo. No meu país costuma-se dizer que ninguém sobe nenhuma árvore com as mãos nos bolsos. Esta a analogia que terá de tipificar o nosso percurso. Vamos, de forma solidária, retirar essas mãos dos bolsos se quisermos ver os nossos países num patamar ainda melhor. Em mais este Encontro Anual da AULP, deveremos debater as condições de base para o desenvolvimento da formação e capacitação dos atuais quadros, da emergência das principais áreas de pesquisa comuns, procurando novas formas de cooperação internacional académica, científica, tecnológica, artística e criativa, novos modelos de desenvolvimento não necessariamente baseados no crescimento económico, identificando novos atores, discutindo o impacto e as realidades sociais de cada país e até região", discurso de abertura do Professor Jorge Ferrão, Presidente da AULP em 2014.

\section{$O$ apoio do continente africano}

Após a realização de Encontros em Portugal, Brasil e Macau, Moçambique é o primeiro país africano que acolhe a AULP para a reunião anual, em 1999. O livro de atas do IX Encontro AULP em Maputo, Moçambique, foi subordinado ao tema "Universidade e Mudança" e as comunicações apresentadas giraram em torno das temáticas como a preservação da língua e culturas lusófonas, a mudança nos paradigmas de revisão curricular bem como as perspetivas e os desafios inerentes à cooperação científica e académica nas comunidades dos países de língua portuguesa.

Logo a seguir vem Angola que em 2002 é palco do XII Encontro da AULP, que teve lugar na cidade de Luanda, com o acolhimento da Universidade Agostinho Neto. Nesta edição temática, os mecanismos de financiamento do ensino superior no espaço lusófono, o reconhecimento de competências, o incentivo à mobilidade bem como a problemática da interpenetração da língua e das culturas na comunidade dos países de língua portuguesa foram objeto de análise aprofundada pelos diversos intervenientes.

Em 1986, Cabo-Verde foi o berço da fundação da AULP. Mas só 21 anos depois, em 2007, com a criação da Universidade de Cabo-Verde, é que a AULP reúne em terras cabo-verdianas para realizar o XVII Encontro subordinado à temática - "A Universidade em Rede". A presente edição constitui o relatório científico do debate e das discussões desencadeadas em torno da problemática das Redes Universitárias na Investigação Científica, das Pós-Graduações em Rede e da Diversidade da Língua Portuguesa. Na sequência deste Encontro realizou-se um seminário interdisciplinar intitulado "Agricultura, Ensino e Investigação: Redes de Pós-Graduação em Língua Portuguesa" organizado pela ASSESCA-PLP (Associação de Ensino Superior em Ciências Agrárias dos Países de Língua Portuguesa), um seminário 
sobre "A Interdisciplinaridade da Investigação Científica e Tropical" a cargo do Instituto de Investigação Científica e Tropical (IICT) e dissertou-se sobre a situação da "Língua Portuguesa no Mundo" numa organização da AULP em estreita colaboração com Instituto Internacional de Língua Portuguesa (IILP).

O regresso a Angola ocorre em 2009, explorando o tema "Direito, Cidadania e Desenvolvimento" no XIX Encontro da AULP, realizado novamente em Luanda. No Encontro foram debatidos os problemas relacionados com o desenvolvimento da investigação científica, a densificação das redes sociais, as questões institucionais relacionadas com a transferência dos valores sociais, as orientações normativas, assim como as reformas legislativas em curso nos diferentes terrenos onde se inscreve a lusofonia. O Encontro deu também particular atenção a dois sectores, a promoção da educação e da cidadania a partir das novas tecnologias e, a reflexão sobre os modelos de desenvolvimento, procurando identificar as potencialidades da maior intersecção entre a Universidade e a sociedade, passíveis no futuro de maior aprofundamento. Foi ainda abordado no painel final do Encontro, a problemática da língua e da cultura como meio de promover o melhor relacionamento nos âmbitos científico, tecnológico, artístico, cultural e diplomático entre os povos dos países da CPLP. Paralelamente, houve um conjunto de realizações que se traduziram em Exposições, lançamentos de novas Edições e outros eventos culturais.

A AULP volta a Moçambique em 2012 para o XXII Encontro da AULP, subordinado à temática - "Ensino Superior e Investigação Científica no Espaço da CPLP", realizado em Maputo. "Assim, o facto de nos reunirmos sob o lema o Ensino Superior e a Investigação no Espaço da CPLP vai ao encontro com aquilo que são as nossas aspirações. As mesas redondas e as sessões paralelas sobre a acreditação e qualidade no ensino superior, mobilidade, internacionalização e ensino superior privado no espaço da CPLP não são problemas de um único país, de uma sub-região, ou região, mas de todos nós. É esta partilha dos mesmos desafios, mas também anseios e valores, que justifica que nos reunamos aqui em Maputo neste XXII Encontro das universidades de língua portuguesa. Por outro lado, a realização deste Encontro no início da uma década, que é sempre um período propício para se planificar as décadas seguintes, deve servir de motivo para que nós também, como gestores das IES, bem como os seus beneficiários, nos detenhamos em algumas reflexões sobre o ensino superior para os próximos 10 ou 25 anos.", Orlando Quilambo, Reitor da Universidade Eduardo Mondlane.

"Novos desafios para o Ensino Superior após os objetivos de desenvolvimento do milénio (ODM)" foi o tema principal de debate no XXV Encontro da AULP em Cabo Verde, sendo o primeiro em que a Universidade de Macau está na presidência. "É com uma enorme honra e privilégio que estou hoje aqui presente para encerrar o XXV encontro da AULP e agradecer a presença dos mais de 400 
participantes dos vários países de língua portuguesa e Macau, RAEM, que contribuíram para o sucesso deste encontro e representaram as instituições de ensino superior membros da nossa associação. É um privilégio assistir à extensa adesão às atividades promovidas pela nossa associação - foram aqui apresentadas mais de 60 comunicações sobre os temas "Políticas e estratégias de cooperação para o desenvolvimento nos países de língua oficial portuguesa e perspetivas para o pós-ODM"; "A difusão e desenvolvimento da língua e literatura portuguesa"; "A plataforma continental marítima"; "A presença do mar na cultura expressa em português" e "Novos desafios das Universidades membros da AULP". Quero também deixar um especial agradecimento à Universidade de Cabo Verde, em especial à Senhora Reitora, Professora Doutora Judite Nascimento, e a toda a comissão organizadora, que tão calorosamente nos recebeu para debatermos os "Novos desafios para o Ensino Superior após os objetivos de desenvolvimento do milénio (ODM)". Não posso deixar também de agradecer ao Senhor General Rocha Vieira não só pela sua presença neste evento, mas também pelo seu precioso contributo para o percurso de sucesso da AULP ao longo destes 28 anos. A fundação da AULP na cidade da Praia em 1986, bem como o momento inaugurador para a Universidade de Cabo Verde no ano de 2007, data do primeiro Encontro da AULP em Cabo Verde, promovida pelo então Reitor da Uni-CV, o Professor Doutor António Correia e Silva, atual ministro do Ensino Superior, Ciência e Inovação que também nos deu o privilégio na sua presença ao longo deste encontro, tornaram Cabo Verde o local ideal para homenagear o Senhor General Rocha Vieira enquanto membro honorário da AULP. A atual sede da associação existe graças ao Senhor General no período em que era Governador de Macau. A todos os que contribuíram para o engrandecimento institucional da AULP, um muito obrigado.", Rui Martins, Presidente da AULP em representação do Reitor da Universidade de Macau.

\section{Balanço e conclusões}

Em 30 anos de existência, realizaram-se 25 encontros. Destes encontros resultaram a publicação de 23 livros de atas. Dado que a sede fica em Portugal, e os primeiros encontros foram em território português, verifica-se que das 25 reuniões anuais, 9 realizaram-se em Portugal. Brasil e Macau totalizam o mesmo número de encontros: 5, enquanto Moçambique, Angola e Cabo-Verde acolheram cada um 2 eventos. É de referir que Timor-Leste acolheu pela primeira vez o Encontro da AULP em 2016, estando o livro de atas atualmente em fase de edição.

Vários livros de atas, devido ao elevado número de participantes e comunicações, foram publicados em 2 volumes. O primeiro foi em 1998 quando o oriente recebeu pela primeira vez a reunião anual (Macau - VIII Encontro), tomando-se a mesma decisão em 2010 (Macau - XX Encontro) e finalmente em 2015 (Cabo-Verde - XXV). 
O livro de atas com maior número de páginas, para além da edição dupla de 1998, em Macau, que totalizou mais de 1000 páginas destacando-se, em volume, de todas as outras publicações, foi o de Moçambique, em 2012, com 543 páginas.

Os Encontros com mais participantes não coincidem obrigatoriamente com os livros de atas mais volumosos, dado que muitos oradores não enviaram os seus trabalhos para a sede em tempo útil de serem publicados. Daí que mais recentemente, em 2016, se tenha começado a implementar a política de envio dos trabalhos na altura da inscrição na conferência, pouco depois do resultado da chamada de trabalho, e antes da data do Encontro.

Apesar do número de participantes ter aumentado ao longo dos anos, o número de exemplares impressos veio diminuindo, resultado de restrições económicas e espaço para arquivo dos exemplares excedentes, assim como o advento das novas tecnologias.

\begin{tabular}{|c|c|}
\hline Livro de Atas & Tiragem \\
\hline 1990 - II Encontro & 1000 \\
\hline 1992 - III Encontro & 1000 \\
\hline 1994 - IV Encontro & 500 \\
\hline 1995 - V Encontro & 500 \\
\hline 1996 - VI Encontro (caderno) & 500 \\
\hline \multirow{2}{*}{1998 - VIII Encontro (2 volumes) } & 1000 \\
\hline & 1000 \\
\hline 1999 - IX Encontro & 1000 \\
\hline 2000 - X Encontro & 1000 \\
\hline 2001 - XI Encontro & 1000 \\
\hline 2002 - XII Encontro & 500 \\
\hline 2003 - XIII Encontro & 500 \\
\hline 2004 - XIV Encontro & 750 \\
\hline 2005 - XV Encontro & 750 \\
\hline 2006 - XVI Encontro & 500 \\
\hline 2007 - XVII Encontro & 750 \\
\hline 2008 - XVIII Encontro & 750 \\
\hline 2009 - XIX Encontro & 750 \\
\hline \multirow{2}{*}{2010 - XX Encontro (2 volumes) } & 500 \\
\hline & 500 \\
\hline 2011 - XXI Encontro & 500 \\
\hline 2012 - XXII Encontro & 300 \\
\hline 2013 - XXIII Encontro & 300 \\
\hline 2014 - XXIV Encontro & 300 \\
\hline \multirow{2}{*}{2015 - XXV Encontro (2 volumes) } & 300 \\
\hline & 300 \\
\hline TOTAL & 16750 \\
\hline
\end{tabular}

Tabela 1 - Evolução da tiragem dos livros de atas. 
Como se pode verificar na tabela, inicialmente foram impressos 1000 exemplares, mas desde 2012 que a direção optou por fazer tiragens mais curtas de 300 exemplares como número razoável para distribuição pelas várias instituições de ensino superior membros da AULP, dos vários países de língua portuguesa e Macau - RAEM, China, parceiros e autores dos artigos. No total, a AULP foi responsável pela publicação de 16750 livros de atas, um número significativo.

Simultaneamente, o desenho dos livros de atas sofreu alterações ao longo dos anos. As primeiras capas feitas, entre 1990 e 1998, de cores mais escuras, com as bandeiras dos países de língua portuguesa como pano de fundo. Entre 1999 e 2003, para além das cores escuras nas capas, surge o logótipo da AULP com as bandeiras dos países de língua oficial portuguesa.

Apesar da bandeira da Região Administrativa Especial de Macau (RAEM) ter sido criada em 1999, ano da transferência da soberania de Macau à República Popular da China, apenas em 2003, com o segundo Encontro em Macau, a capa do livro de atas faz referência a esta região. Uma capa simples a verde (cor da bandeira) e a flor de lótus desenhada (flor característica de Macau, presente também na bandeira e que simboliza o desabrochar sob a luz das cinco estrelas, que por sua vez representam a China, traduzindo a prosperidade e o desenvolvimento de Macau).

Entre 2004 e 2010 assiste-se à modernização das capas dos livros de atas, com cores claras e imagens alusivas aos países e cidades de acolhimento. No entanto, em 2011 e 2012 as capas sofrem nova transformação, com cores escuras e sem uma estrutura base que garantisse tratar-se da mesma coleção. Esse aspeto é rapidamente corrigido em 2013, que serve de modelo até à atualidade, em que se recupera o desenho anterior a 2010, estando a principal diferença na contracapa que atualmente serve para colocar também uma fotografia alusiva ao local de realização do Encontro.
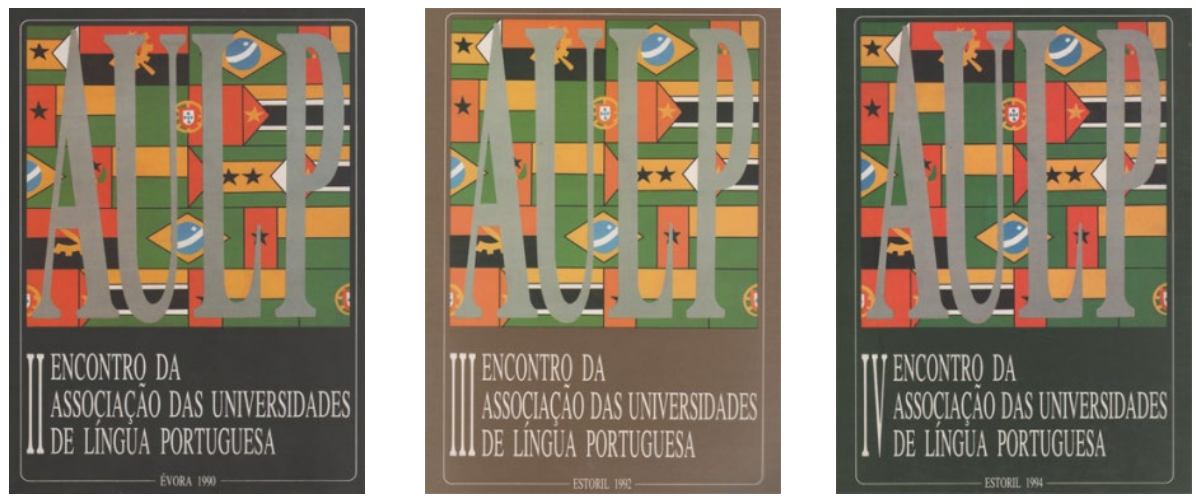

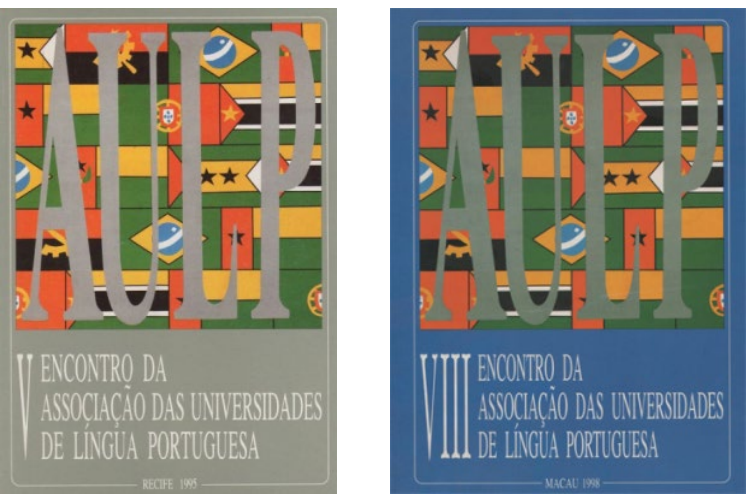

2 - Atas - 1990 a 1998
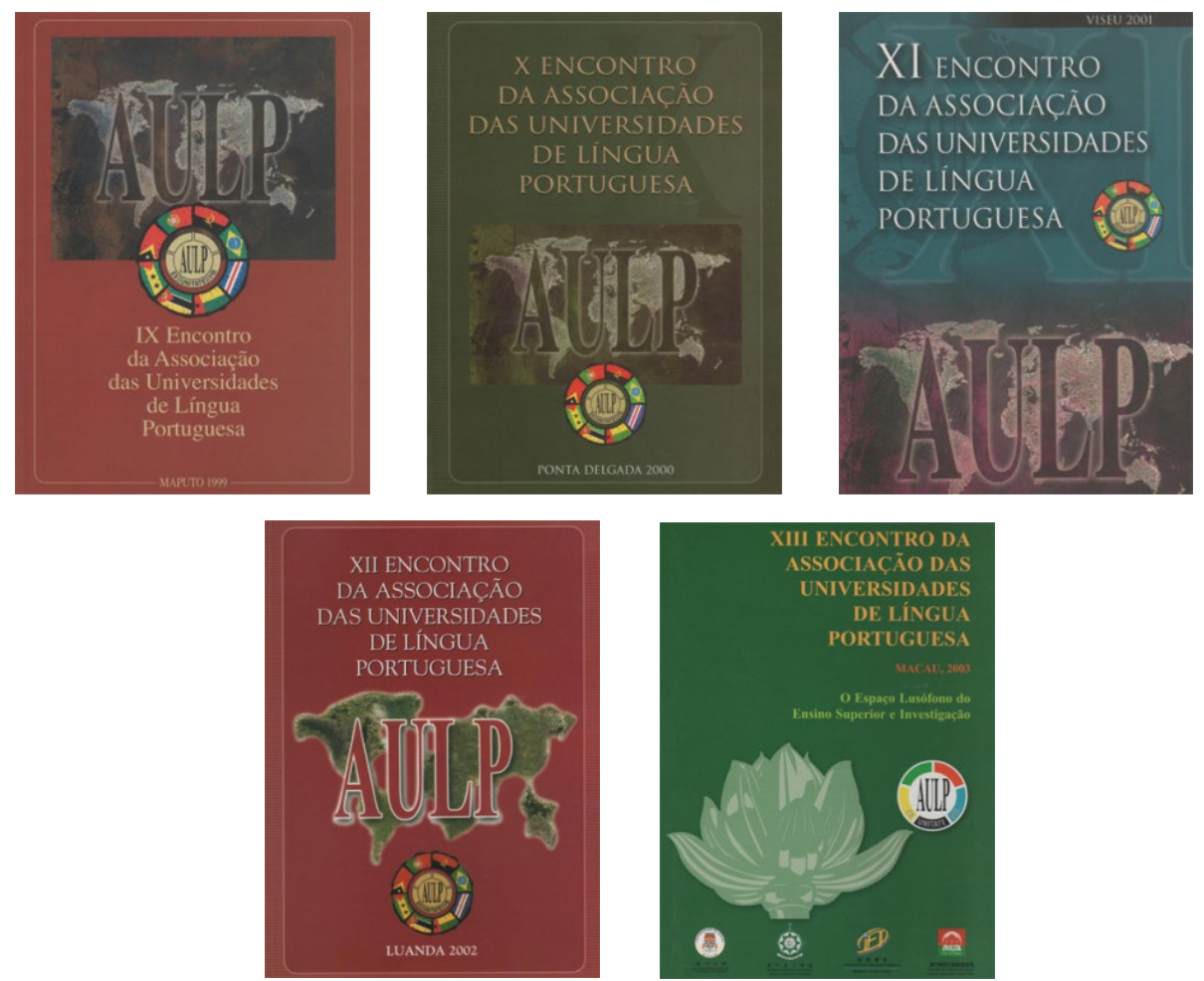

3 - Atas - 1999 a 2003. Destaque para a última capa, alusiva ao XVIII Encontro com referência pela primeira vez a Macau - RAEM, China. 


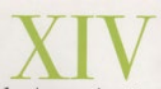

Encontro da Associação das Universidades de Língua Portuguesa

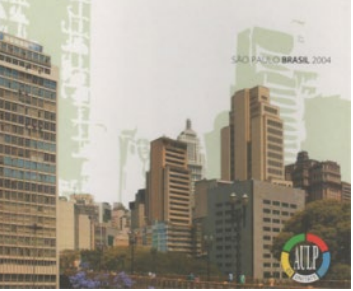

Universidade em Rede

XVII Encontro da Associação das Universidades de Língua Portuguesa

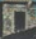

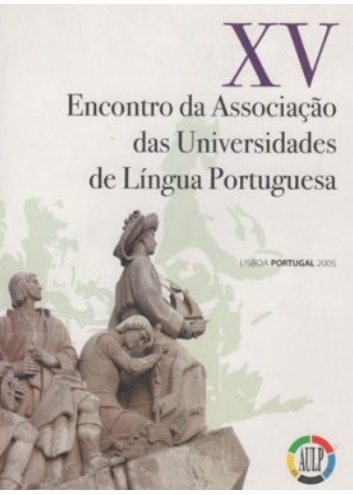

Ciência, Tecnologia

e Desenvolvimento

XVIII Encontro

da Associação das Universidades de Língua Portuguesa

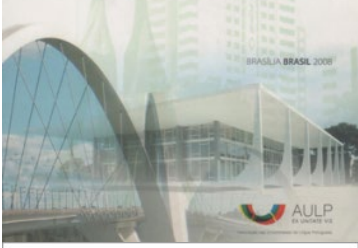

A China, Macau e os Países de Língua Portuguesa

XX Encontro

da Associação das Universidades de Língua Portuguesa

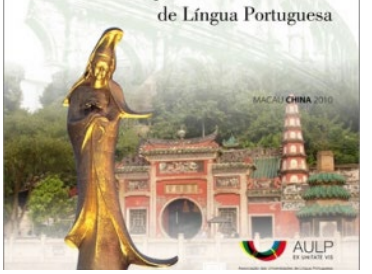

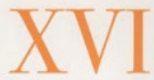

Encontro da Associação das Universidades de Língua Portuguesa

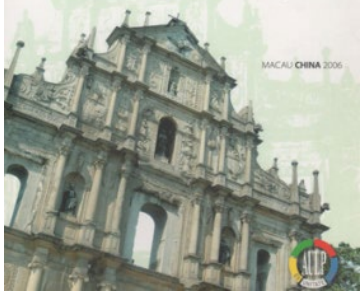

Direito, Cidadania

e Desenvolvimento

XIX Encontro da Associação das Universidades de Língua Portuguesa

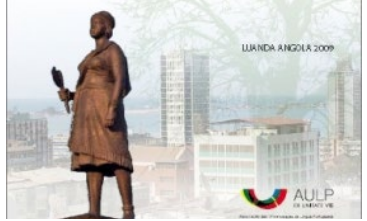

4 - Atas - 2004 a 2010.
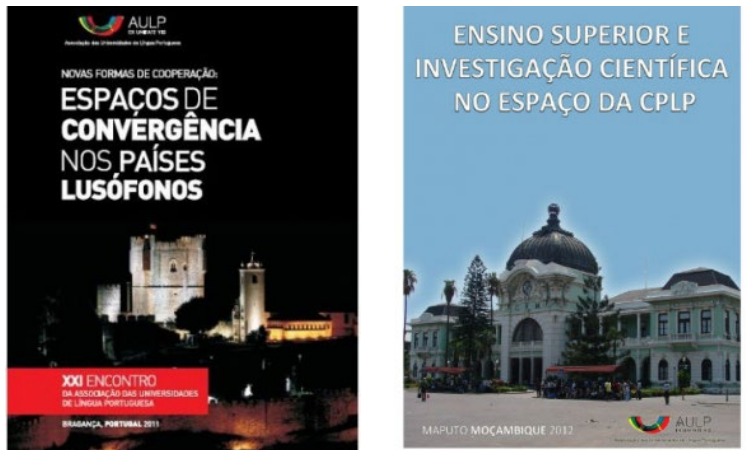

5 - Atas - 2011 e 2012 


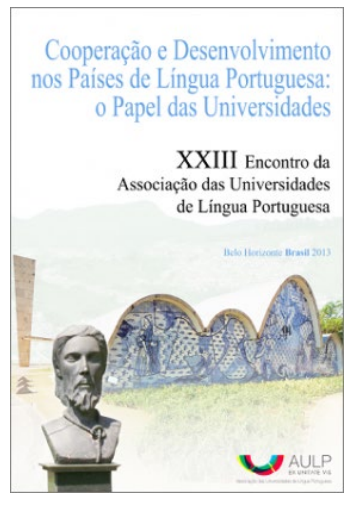

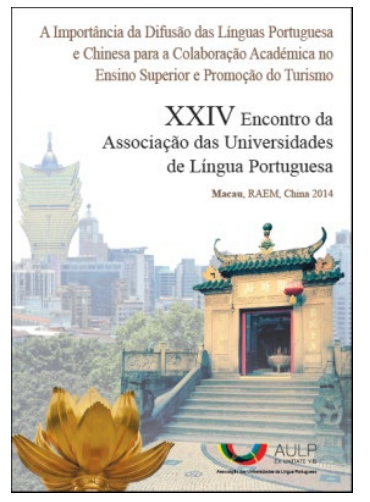

6 - Atas - desde 2013

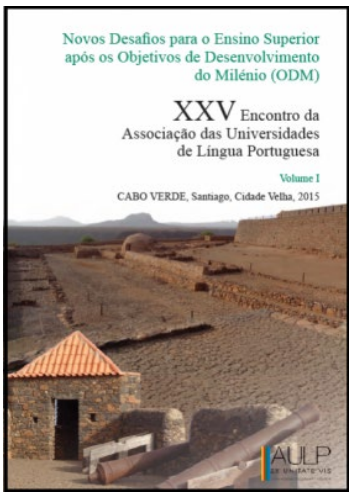

Em suma, os livros de atas constituem um dos pilares das tarefas associativas, resultado dos encontros anuais da AULP. Fazem parte das publicações periódicas da associação e tiveram início pouco depois da fundação da AULP. Com vários números já esgotados, suscitam interesse no meio académico, e a a sede regista vários pedidos de aquisição tanto dos primeiros números, assim como dos mais recentes.

Através do registo das comunicações dos intervenientes que representam as instituições dos vários países de língua oficial portuguesa e Macau, RAEM, China, a AULP contribui assim para o registo dos projetos, preocupações e reflexões do ensino superior no espaço da língua portuguesa. 